\title{
Superlubricity achieved with two-dimensional nano-additives to liquid lubricants
}

\author{
Hongdong WANG, Yuhong LIU* \\ State Key Laboratory of Tribology, Tsinghua University, Beijing 100084, China \\ Received: 15 January 2020 / Revised: 19 April 2020 / Accepted: 26 May 2020 \\ (C) The author(s) 2020.
}

\begin{abstract}
The topic of superlubricity is attracting considerable interest around the world while humanity is facing an energy crisis. Since various liquid superlubricity systems can be commonly achieved on the macroscale in ambient conditions, it is considered an effective solution to reduce unnecessary energy and material losses. However, certain practical problems such as low load-bearing pressure, dependence on hydrogen ions, and relatively long running-in processes still limit its widespread application. Twodimensional (2D) nano-additives with ultrathin longitudinal dimensions can lower the shear resistance between sliding solid surfaces, and thus further optimize the applied conditions. In this review, the latest studies on 2D nano-additives with a combination of various water-based lubricants in the state of superlubricity are reported, typically including black phosphorus (BP), graphene oxide (GO), and layered double hydroxide. During the sliding process, composite lubricants effectively improved the load capacity (up to $600 \mathrm{MPa}$ ), reduced wear, and accelerated the running-in period (within 1,000 s) of the liquid superlubricity system. Both macromechanical experiments and microscopic tests are conducted to precisely analyze various interactions at the interfaces of the nano-additives and solid surfaces. These interactions can be described as tribochemical reactions, physical protection, and adsorption enhancement, and improved wear resistance. This review provides better guidance for applying 2D nanomaterials in liquid superlubricity systems.
\end{abstract}

Keywords: superlubricity; two-dimensional (2D) nanomaterial; lubricant additive; water-based; tribological property

\section{Introduction}

Friction is quite common in daily life, manufacturing, and various other fields. Significant losses (approximately $5 \%-7 \%$ of the gross national product) in material and energy are owed to unnecessary friction [1-3]. Therefore, it has become an urgent challenge to develop good lubrication systems to increase energy efficiency to develop a modern industrial revolution. An ideal state of "superlubricity", in which friction and wear are negligible, was proposed in 1990 by Hirano and Shinjo [4]. This study was conducted assuming the existence of two clean crystal surfaces on a microscale. After theoretical calculations, researchers found that the frictional force vanished between two completely clean solid surfaces in an incommensurate state. Owing to various factors in friction system and measurement limitations, it is almost impossible to achieve the ideal state of "zero friction" on a macroscale at present. As shown in Fig. 1, the superlubricity region is where the sliding coefficient of friction (COF) is less than 0.01 [5]. It is still a significant challenge to accurately measure COF values of less than 0.001 in macroscale. With developments in

* Corresponding author: Yuhong LIU, E-mail: liuyuhong@tsinghua.edu.cn 


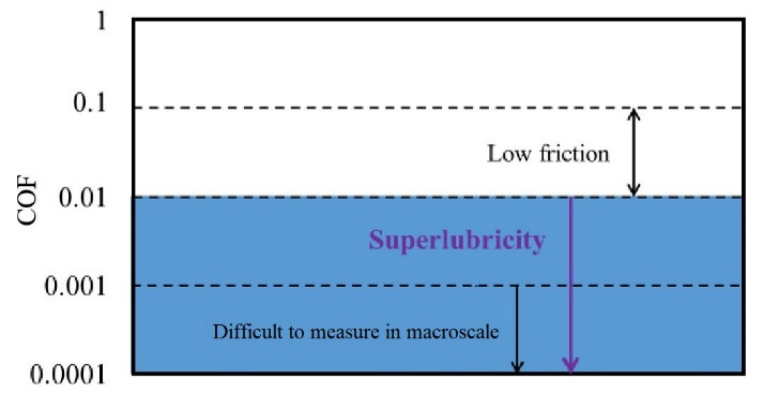

Fig. 1 COF range in superlubricity region.

measurement technology and methods in the past two decades, both theoretical foundations and experimental proof of superlubricity have been constantly produced across different scales $[5,6]$.

Currently, two different ways of achieving superlubricity have been widely reported based on lubricating materials, generally divided into solid and liquid superlubricity. Solid superlubricity achieved on the micro- or nano-scale, is considered as two sliding surfaces with ultralow interaction under specific conditions [7-14]. In 2018, Berman et al. [15] discussed various mechanisms for frictional energy dissipation during the sliding process, which included wear (shear and removal of material from sliding surfaces), molecular deformation (elastoplastic surface defor mation), thermal effects (thermally activated energy barriers), electronic effects (electrostatic transmission), bonding (chemical bonds), phonons (lattice vibrations), environment/chemistry (surface functionalization/ surrounding atmosphere), and structural effects (atoms locking on commensurate surfaces). They also highlighted related studies that introduced twodimensional (2D) materials at the tribological interface to manipulate friction and wear for friction reduction to near zero across scales. However, it is quite difficult to achieve continuous solid superlubricity on the macroscopic scale and maintain stable ultralow COFs under ambient conditions owing to the strict requirements of the environment and the need for relatively perfect material with non-defective crystals $[16,17]$.

In contrast, it was also reported that ultralow COFs can be obtained using various liquid lubricants, which is called "liquid superlubricity". In the past few years, investigations into research topics, such as water-based ceramic lubrication [18-21], polymer molecular brush lubrication [22-25], and polyhydroxy aqueous solution [26-29], have been widely reported. Since liquid superlubricity can be achieved on the macroscale under an ambient environment, it is very likely to be utilized in practical production conditions.

In our previous studies, a novel liquid superlubricity system of phosphoric acid solution between sliding solid surfaces of silicon nitride $\left(\mathrm{Si}_{3} \mathrm{~N}_{4}\right)$ and glass was investigated with an ultralow COF of 0.004 , as shown in Fig. 2. After approximately $600 \mathrm{~s}$ of the running-in period, the COF remained quite stable in the range of $0.003-0.004$ for more than $3,000 \mathrm{~s}$. It was hypothesized that phosphoric acid and water molecules formed a nanosized aqueous tribofilm with hydrogen-bonded network structure, which was induced by the shear and pressure effects [30]. Then, a phosphoric acid superlubricity system was applied under different sliding solid surfaces (e.g., ceramics, silicon oxide, sapphire, and ruby) and working conditions [31-33]. Afterwards, the liquid superlubricity system was further promoted to a mixture of polyhydroxy alcohol (e.g., propanol to propanetriol, 1,2-ethanediol to 1,5-pentanediol, and diethylene glycol to pentaethylene glycol) and an acid solution. It was found that the superlubricity state was closely related to the concentration of polyhydroxy alcohol and its number of hydroxyl groups contained [26-29]. Moreover, it was recently reported that ionic liquids (ILs, e.g., the combination of cations of $\mathrm{Li}^{+}, \mathrm{Na}^{+}$, or $\mathrm{K}^{+}$, anions of $\mathrm{PF}_{6}^{-}, \mathrm{BF}_{4}^{-}$, or $\mathrm{NTf}_{2}^{-}$, and water-soluble molecules of ethylene glycol) were utilized to improve the performance of superlubricity systems. It was observed that the

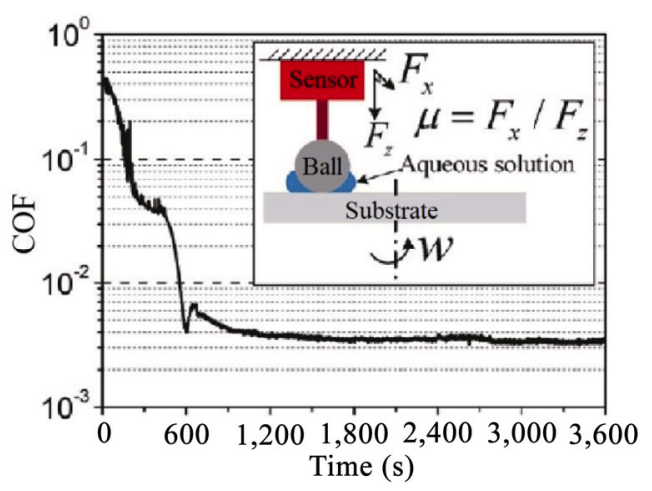

Fig. 2 COF of $\mathrm{H}_{3} \mathrm{PO}_{4}$ aqueous solution $(\mathrm{pH} 1.5) . F_{x}$ is friction force, $F_{z}$ is applied load, and $\mu$ is COF. Reproduced with permission from Ref. [30], (C) American Chemical Society 2011. 
monovalent metal cation with a small size was beneficial in improving the wear condition [34-36]. At present, various superlubricity systems achieved by different lubricants after a period of running-in show great potential for industrial applications.

In 2019, Ge et al. [43] reviewed the advances in liquid superlubricity systems on the macroscale and outlined corresponding mechanisms for various liquid lubricants. It was summarized that only a few liquid lubricants exhibited superlubricity behavior. The mechanism of various superlubricity systems can be attributed to factors, such as silica layers and hydrodynamic lubrication for water, the tribochemical layer, and hydrogen-bond network for viscous lubricants, the hydration layer for polymer and salt solution, and the stern layer and hydrogen-bond network for acid-based lubricants. The reliability and stability of a lubricating system is strongly influenced by the presence of water and hydrogen ions [26, 43]. The statistical results in Table 1 indicate that there are still significant challenges in further improving the load-carrying capacity.

Therefore, it is quite promising to combine the liquid superlubricity of water-based lubricants and solid superlubricity of 2D nanomaterials to optimize the superlubricity system, and reveal their mechanism, regulation, and potential applications in future. Until now, most related studies have focused on additives in oil-based lubricants and small amount in waterbased lubricants, but few on superlubricity lubricants.

Table 1 Liquid superlubricity systems with different sliding solid surfaces, lubricants, and final contact pressures (MPa) in superlubricity state.

\begin{tabular}{|c|c|c|}
\hline Solid surfaces & Lubricants & $\begin{array}{c}\text { Contact } \\
\text { pressure }(\mathrm{MPa})\end{array}$ \\
\hline $\mathrm{Si}_{3} \mathrm{~N}_{4} /$ sapphire & Salt $_{(\mathrm{aq})}[37]$ & 170 \\
\hline $\mathrm{Si}_{3} \mathrm{~N}_{4} / \mathrm{Si}_{3} \mathrm{~N}_{4}$ & $\mathrm{LiPF}_{6}$-based $\mathrm{IL}_{(\mathrm{aq})}[36]$ & 132 \\
\hline $\mathrm{Si}_{3} \mathrm{~N}_{4} / \mathrm{Si}_{3} \mathrm{~N}_{4}$ & Water [19] & $<10$ \\
\hline $\mathrm{Si}_{3} \mathrm{~N}_{4} / \mathrm{SiO}_{2}$ & PEG + boric $\operatorname{acid}_{(\mathrm{aq})}[38]$ & 111 \\
\hline $\mathrm{Si}_{3} \mathrm{~N}_{4} / \mathrm{SiO}_{2}$ & $\mathrm{IL}_{(\mathrm{aq})}[35]$ & 37 \\
\hline Ruby/sapphire & $\mathrm{H}_{3} \mathrm{PO}_{4(\mathrm{aq})}[33]$ & 95 \\
\hline $\begin{array}{l}\text { Poly tetrafluoro- } \\
\text { ethylene/Poly- } \\
\text { vinyl phosphonic } \\
\text { acid }\end{array}$ & $\begin{array}{c}\text { Phosphate-buffered } \\
\text { saline [39] }\end{array}$ & 63.5 \\
\hline $\mathrm{Si}_{3} \mathrm{~N}_{4} / \mathrm{Al}_{2} \mathrm{O}_{3}$ & $\begin{array}{l}\text { Polyalkylene glycol } \\
(\mathrm{PAG})_{(\mathrm{aq})}[40]\end{array}$ & 60 \\
\hline Steel/Steel & $\begin{array}{l}\text { Glycerol }_{(\mathrm{aq})}[41], \\
\text { 1,3-diketone [42] }\end{array}$ & $40-15$ \\
\hline
\end{tabular}

\section{Nano-additives in liquid lubricants}

\subsection{Superlubricity enabled by nanodiamonds in glycerol colloidal solution}

In 2015, Chen et al. [44] introduced nanoparticles into the liquid superlubricity lubricant and investigated the lubricant additive of nanodiamonds in glycerol colloidal solution between steel ball and disk, as shown in Fig. 3. Compared to the glycerol solution, less wear condition was obtained with only $0.01 \mathrm{wt} \%$ nanodiamond additives in colloidal solution. It was shown that the diameter of wear scar on the ball was reduced by $32.5 \%$, and thus the contact pressure increased from about 23.96 to $52.55 \mathrm{MPa}$ between the sliding surfaces during the superlubricity period. The ultralow COF was demonstrated as a result of both the hydrogen bond layer of the nanoparticle additives and the hydrodynamic effect of liquid lubricant. The rolling effect of the nanodiamonds with a hydrophilic surface was suggested to cause the reduced wear volume. This study could provide guidance for optimizing the applied conditions of liquid superlubricity.

\subsection{D nanomaterials as lubricant additives}

However, there have been fewer studies on 2D nanomaterials as additives to achieve superlubricity. Nowadays, various 2D nanomaterials as lubricant additives are commonly utilized in industrial production processes to reduce friction and wear, and thereby improving production efficiency, extending the component life, and increasing the energy transfer efficiency. These have been widely

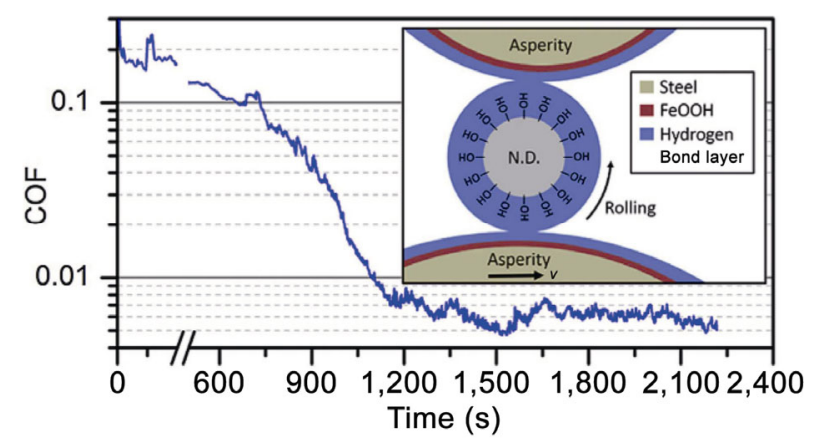

Fig. 3 Superlubricity is achieved between steel surfaces with nanodiamonds glycerol colloid solution. Reproduced with permission from Ref. [44], (C) Elsevier Ltd 2015. 
investigated in tribological research in recent years owing to their unique physical structure and special chemical properties $[45,46]$. Among them, carbon nanomaterials (e.g., graphene and its derivatives) and transition metal disulfides (e.g., molybdenum disulphide) are the most popular ones [47-49]. In addition, owing to their special structure and various chemical compositions, other 2D materials such as layered double hydroxide (LDH), metal or covalent organic framework materials, hexagonal boron nitride, and graphite-like carbon nitride also show superior tribological properties [50-54].

In 2015, Chen et al. [55] dispersed $1 \mathrm{wt} \%$ ultrathin $\mathrm{MoS}_{2}$ nanosheets in liquid paraffin, and the results indicated that the highest load capacity was improved from less than $50 \mathrm{~N}$ to more than $2,000 \mathrm{~N}$, as shown in Fig 4. Compared to three-dimensional (3D) nanoparticles, it was much easier for 2D nanosheets with ultrathin shape to enter the contact area of two sliding solid surfaces and then form a protective film to prevent seizure. In addition, ultrathin $\mathrm{MoS}_{2}$ sheets of various lateral sizes were compared, and the larger sheets were found to show better lubrication performance [56]. In 2016, Zhao et al. [57] prepared layered graphene and $\mathrm{MoS}_{2}$ nano-additives, and applied them to a linear oscillator motor for tribological evaluation. The results showed $\mathrm{MoS}_{2}$ nanosheets adsorbed on smooth surfaces, and thus COF could be decreased to 0.04 . However, the tribological properties of multilayer graphene are unstable owing to agglomeration and crystal defects. The tribological properties of graphene with different layers and layer spacing through exfoliation were further investigated. It was demonstrated that graphene additives with a higher degree of peeling would become ordered under friction testing, and the tribological properties were improved [58]. In addition, it was reported that the tribological properties can be improved by adding graphene oxide (GO)containing composite materials, which were doped with nanoparticles of $\mathrm{Ni}$ [59], $\mathrm{Cu}$ [60], $\mathrm{Au}$ [61], $\mathrm{LaF}_{3}$ [62], and $\mathrm{TiO}_{2}$ [63]; nanocomposites of hollow IF$\mathrm{MoS}_{2}$ [64]; and multi-walled carbon nanotubes (MWCNT) [65]. The friction-reducing performance
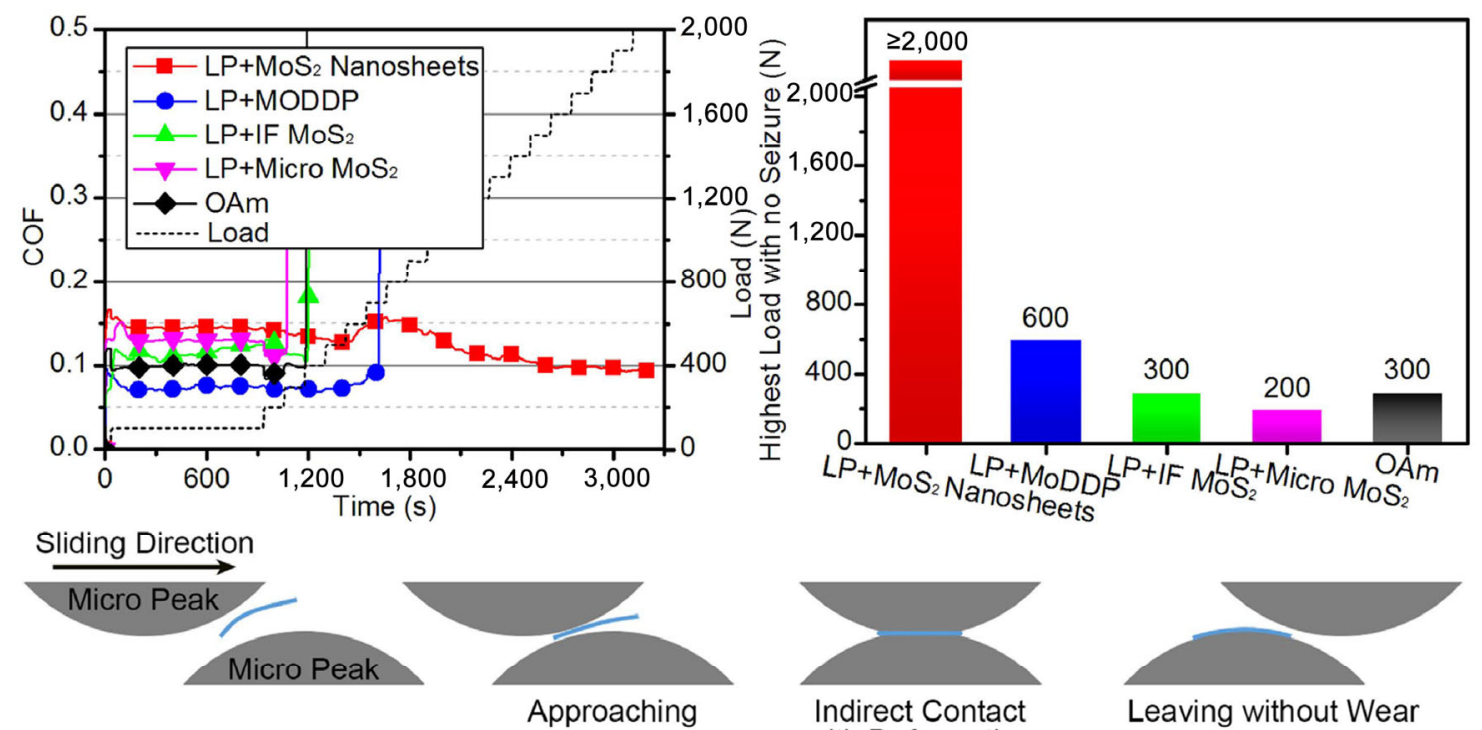

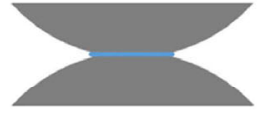

Indirect Contact with Deformation

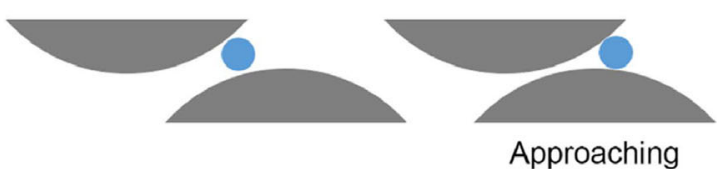

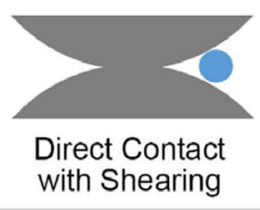

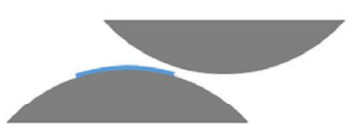

Leaving without Wear

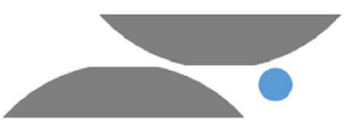

Leaving with Wear

Fig. 4 Results of the load-climbing tribological tests and schematic of the lubrication mechanism of 2D nanosheets and 3D nanoparticles. Reproduced with permission from Ref. [55], (C) Springer Nature 2015. 
and anti-wear properties of the lubrication system were significantly improved with these lubricant additives of graphene-rich composites. This can be attributed to their synergistic effect and the occurrence of tribochemical reactions between sliding solid surfaces under relatively high contact pressure.

Among the wide variety of 2D materials and ongoing research conditions, certain representative 2D materials with hydrophilic groups such as black phosphorus (BP), GO, and LDH can achieve good dispersion and exhibit excellent tribological performance. This review mainly focuses on these nanomaterials and discusses their tribological and superlubricity performance as additives in oil, waterbased, and superlubricity lubricants. The latest research on superlubricity enabled with 2D nanomaterials has focused on the topics of tribochemical reaction, physical protection, improved wear resistance, and adsorption enhancement. The superlubricity behavior and mechanism of these 2D nanomaterials as additives in lubricants will be described in detail.

\section{BP as lubricant additive}

\subsection{BP additive in oil-based lubricant}

In 2018, Wang et al. [66] prepared BP nanosheets as oil-based lubricant additives. In addition, the tribological properties of $\mathrm{MoS}_{2}$ and GO nanosheets were investigated for comparison as oil-based lubricant additives. These lubricant additives demonstrated similar lubrication performance at low loads, where the maximum Hertzian contact pressure varied from 978 to 1,870 MPa. However, the BP nanosheets dispersed in base oil (hexadecane) exhibited optimal extreme pressure resistance and bearing capacity, where the highest load with no seizure reached 2,000 N. Compared to the three oil-based lubricant additives at ultralow concentration, BP also showed the best tribological properties at the lowest concentration of $0.1 \mathrm{ppm}$, while that of GO was $5 \mathrm{ppm}$ and $\mathrm{MoS}_{2}$ was $0.5 \mathrm{ppm}$. The lubrication mechanism of BP nanosheets as additives can be summarized as follows. It is easy for ultrathin BP nanosheets to enter the contact area when the asperities are approaching, and these nanosheets can prevent their direct contact as the load pressure is applied to the sliding solid surfaces. In addition, both the shearing force in lubricant and plastic deformation of the substrate are beneficial for improving wear resistance.

\subsection{Superlubricity enabled by BP in water: Tribochemical reaction}

In 2018, Wang et al. [67] utilized a new type of 2D material, BP, as a water-based lubricant additive that showed excellent performance. The preparation of $\mathrm{BP}-\mathrm{OH}$ and the water-based dispersion effect are illustrated in Fig. 5(a), in which BP powder was prepared with red phosphorus and sodium hydroxide using a high-energy ball milling technique [67]. Subsequently, the surface of the final product (marked as BP-OH) was successfully hydroxylated so that it is uniformly dispersed in water, and applied between the $\mathrm{Si}_{3} \mathrm{~N}_{4}$ ball and $\mathrm{SiO}_{2}$ plate for the friction test in a rotational mode. After a relatively long running-in process (approximately 3,600 s), the COF dramatically decreased and entered the region of superlubricity (between 0.0006 and 0.006), as shown in Fig. 5(b).

With a long running-in process, the $\mathrm{BP}-\mathrm{OH}$ nanosheets were exfoliated and adsorbed on the sliding solid surfaces. As illustrated in Fig. 5(c), a tribochemical reaction took place as water molecules rapidly adsorbed on the surface of the $\mathrm{BP}-\mathrm{OH}$ nanosheets. Consequently, silica gel was formed between the ceramic surfaces. This could maintain a robust superlubricity behavior with a minimum COF of 0.0006 and support a significant load capacity. In this study, a relatively wide range of $\mathrm{BP}-\mathrm{OH}$ concentration was tested, and different sliding speeds were explored for the friction test. As the concentration of $\mathrm{BP}-\mathrm{OH}$ increased from $1 \mathrm{wt} \%$ to $7 \mathrm{wt} \%$, the minimum COF decreased from 0.003 to 0.0006 , and the running-in process decreased as well. A critical velocity of $38 \mathrm{~mm} / \mathrm{s}$ was considered an important condition for achieving superlubricity. In a friction test, as the superlubricity state was achieved and the velocity was changed to $0.3 \mathrm{~mm} / \mathrm{s}$, the COF gradually increased to 0.4 . However, as the sliding velocity increased back to the critical value $(38 \mathrm{~mm} / \mathrm{s})$ or higher, no additional running-in process was needed to recover the state of superlubricity. Since a relatively long time was necessary for the 


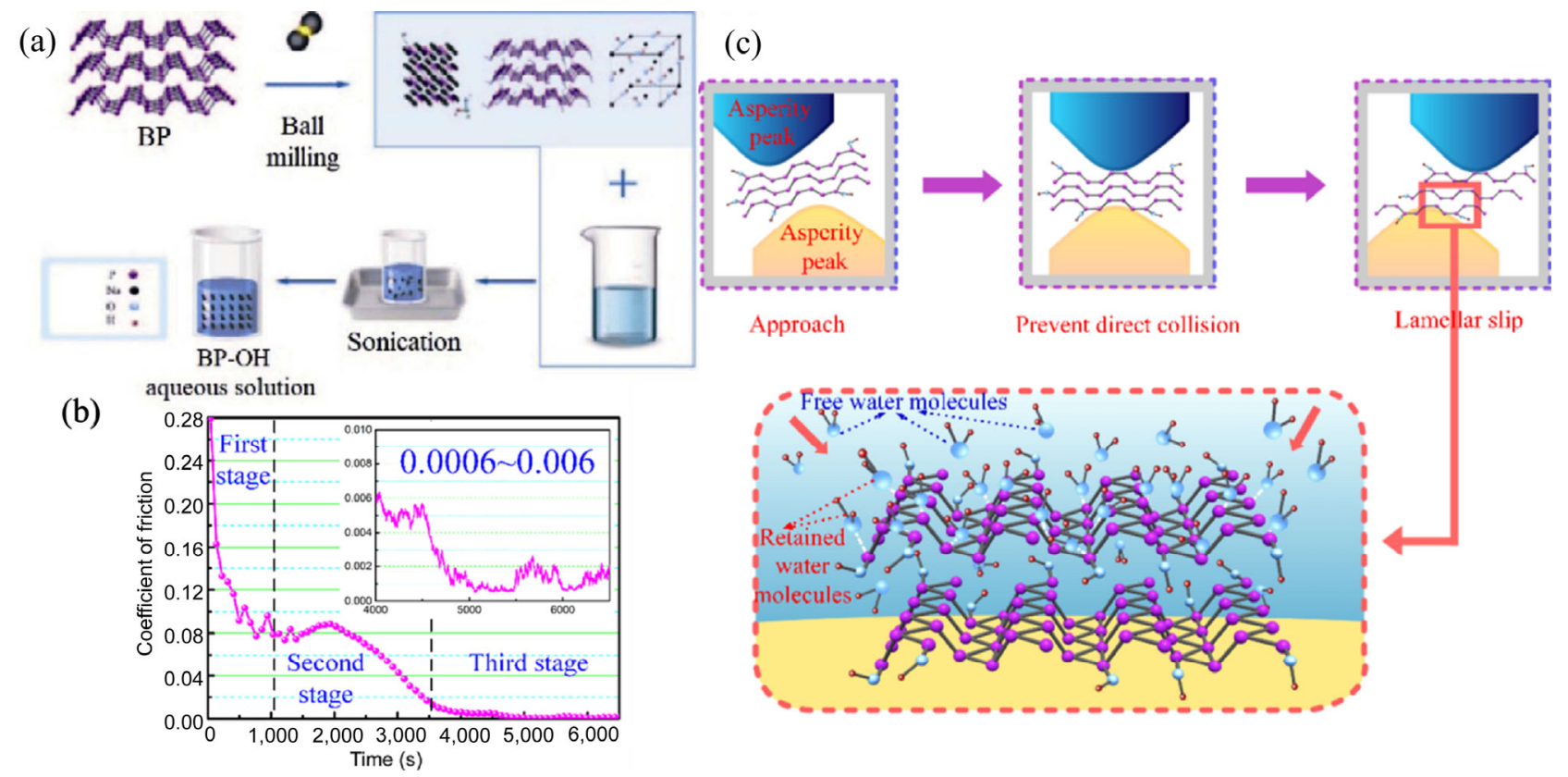

Fig. 5 (a) Preparation of BP-OH nanosheets. (b) $\mathrm{COF}$ of $7 \mathrm{wt} \% \mathrm{BP}-\mathrm{OH}$ aqueous solution. (c) Protective effect of BP-OH nanosheets between asperities during the friction period and schematic of dynamically retained water around the surface of BP-OH nanosheets. Reproduced with permission from Ref. [67], (C) American Chemical Society 2018.

occurrence of the tribochemical reaction, it is still a significant challenge in exploring 2D nanomaterial additives to greatly shorten the running-in period before entering superlubricity and improve the stability of superlubricity systems.

\section{GO as lubricant additive}

\subsection{GO additive in water}

In 2014, Kinoshita et al. [68] investigated the tribological properties of GO monolayer sheets (the lateral size ranged from 10 to $50 \mu \mathrm{m}$ ) as additives in water-based lubricants and their potential applications. Compared to the results of lubrication by purified water $(\mathrm{COF}>0.4)$ and water-based emulsion lubricant ( $\mathrm{COF} \approx 0.12$ ), a low COF (approximately 0.05) was obtained by GO dispersion. Moreover, no obvious surface wear was found even after 60,000 cycles of friction testing. The scanning electron microscope (SEM) images and energy dispersive $X$-ray spectroscopy (EDX) results suggest that the GO sheets adsorb on the ball and flat plate during the sliding process and may behave as protective coatings on both solid surfaces.

\subsection{Superlubricity enabled by synergy of GO and ethaneidol: Physical protection}

In 2018, a robust macroscale superlubricity state $(\mu=$ 0.0037) between sliding solid surfaces of $\mathrm{Si}_{3} \mathrm{~N}_{4}$ $\mathrm{SiO}_{2}$ with synergistic effect of GO nanoflakes (GONFs) and ethanediol (EDO) in a rotatory mode was investigated by Ge et al. [70]. As shown in Fig. 6(a), a modified Hummers method was adopted to prepare GONFs with an oxygen content of 30\%$40 \%$. The atomic force microscopy (AFM) technique was utilized to confirm their lateral dimension of 200-400 nm and a thickness of $0.8 \mathrm{~nm}$, as shown in Fig. 6(b). GONFs have a good dispersion effect in water-based lubricants owing to the hydrophilic oxygen-containing groups on their surface. Subsequently, aqueous solutions of GONFs, EDO, and GONFs-EDO were prepared to explore the synergistic effects of GONFs and EDO. Their tribological performances were evaluated using a universal microtribotester in the rotation mode. As shown in Fig. 6(c), the COF of the GONFs decreased from 0.35 to 0.013 ; the COF of EDO gradually reduced initially and then increased to 0.012 by the end of the test. The high COF for water can be attributed to the lack of formation of an 

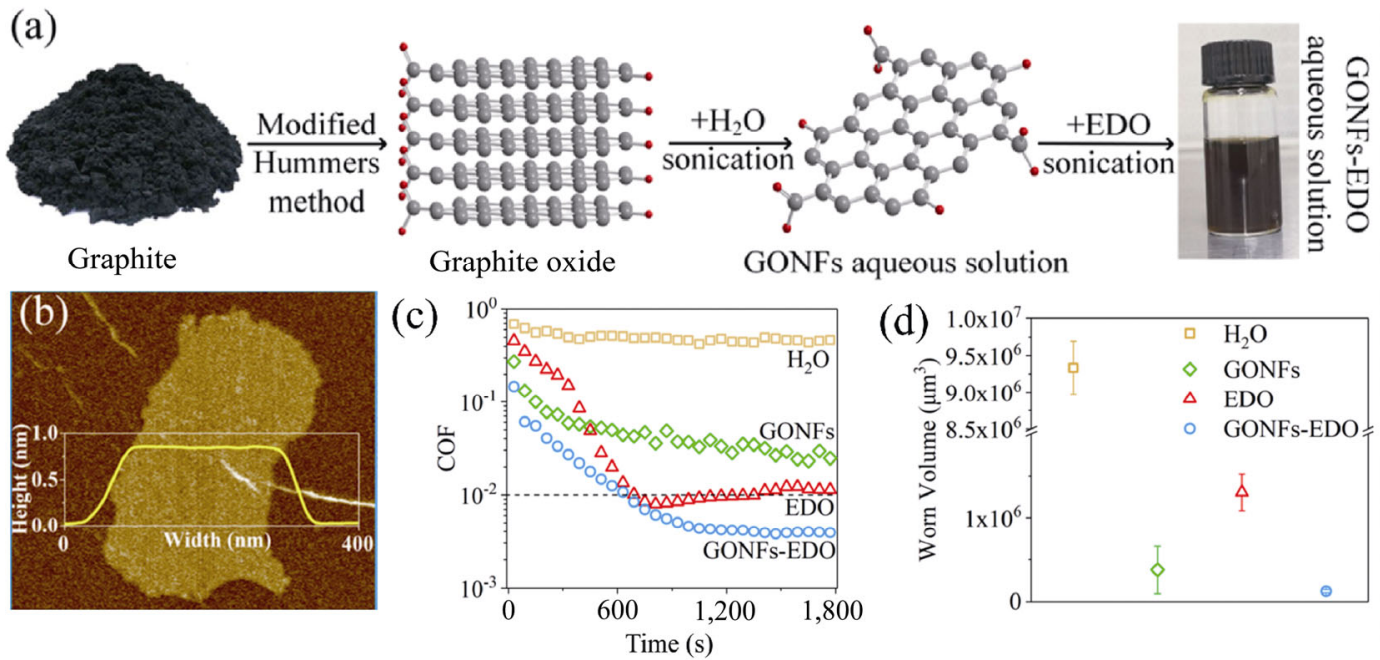

Fig. 6 (a) Preparation of GONFs-EDO aqueous solution; (b) AFM image of GONFs on mica; (c) COF and (d) wear conditions of water and aqueous solutions of GONFs, EDO, and GONFs-EDO. Reproduced with permission from Ref. [69], (C) American Chemical Society 2018 .

effective lubricating film. However, the COF of the GONFs-EDO aqueous solution gradually reduced to the superlubricity region after $600 \mathrm{~s}$ running-in period. Meanwhile, the wear condition also improved, and the wear volume of the surface lubricated by GONFs-EDO $\left(5.1 \times 10^{4} \mu \mathrm{m}^{3}\right)$ was only $5 \%$ of that lubricated by $\operatorname{EDO}\left(1.3 \times 10^{6} \mu^{3}\right)$, as shown in Fig. $6(\mathrm{~d})$.

This study also applied various loads from 2 to $4 \mathrm{~N}$, and superlubricity could be achieved as the contact pressure was no higher than $111 \mathrm{MPa}$. After the friction test, the topographies of the contact area lubricated by GONFs-EDO were analyzed using SEM and Raman spectroscopy, which demonstrated that GONFs were adsorbing on both sliding solid surfaces. The HRTEM images of the adsorbed GONFs after the friction test showed that the thickness (approximately $10 \mathrm{~nm}$ ) was much larger than those of the original GONFs, but the inner layer structure (approximately $0.45 \mathrm{~nm}$ ) remained stable. This indicated that GONFs in EDO solution might stack on sliding solid surfaces, and they provide better protection to prevent the direct contact of asperities. It was easy for the adsorbed GONF layers to slide between the approaching asperities. Thus, it was proposed that the low shear between GONF laminates resulted in friction reduction and ultralow wear conditions in the contact area during the running-in period. Relatively low shear stress existed between the hydrated GONF and EDO molecules and the superlubricity can be achieved in the boundary lubrication regime. Consequently, it was demonstrated that superlubricity might be achieved by the physical protection of GONFs and the synergistic effect of GONFs and EDO molecules.

\subsection{Combination of GO and ionic liquid: Improved wear resistance}

It is necessary to improve the load-bearing capacity of superlubricity to the level of actual working conditions to realize its widespread application potential. As for the friction test, it was relatively high for the initial contact pressure (even on the order of GPa) between sliding solid surfaces, but the load-bearing capacity in the superlubricity region was quite low. This was caused by the mechanical collisions during the running-in period. Recently, robust macroscale superlubricity was achieved with a combination of GO and ionic liquid, in which the corresponding extreme contact pressure reached $600 \mathrm{MPa}$ between $\mathrm{Si}_{3} \mathrm{~N}_{4}$ /sapphire solid surfaces in a rotatory mode [70]. A composite IL + GO aqueous solution was prepared by dispersing as-synthesized [Li(EG)]PF 6 (Fig. 7(a)) in GO aqueous solution.

Friction tests were then conducted with the lubrication of $30-\mu \mathrm{L}$ IL aqueous solution and IL + $0.03 \%$ GO aqueous solution under a load of $3 \mathrm{~N}$ and a relative sliding velocity of $100 \mathrm{~mm} / \mathrm{s}$. As shown 


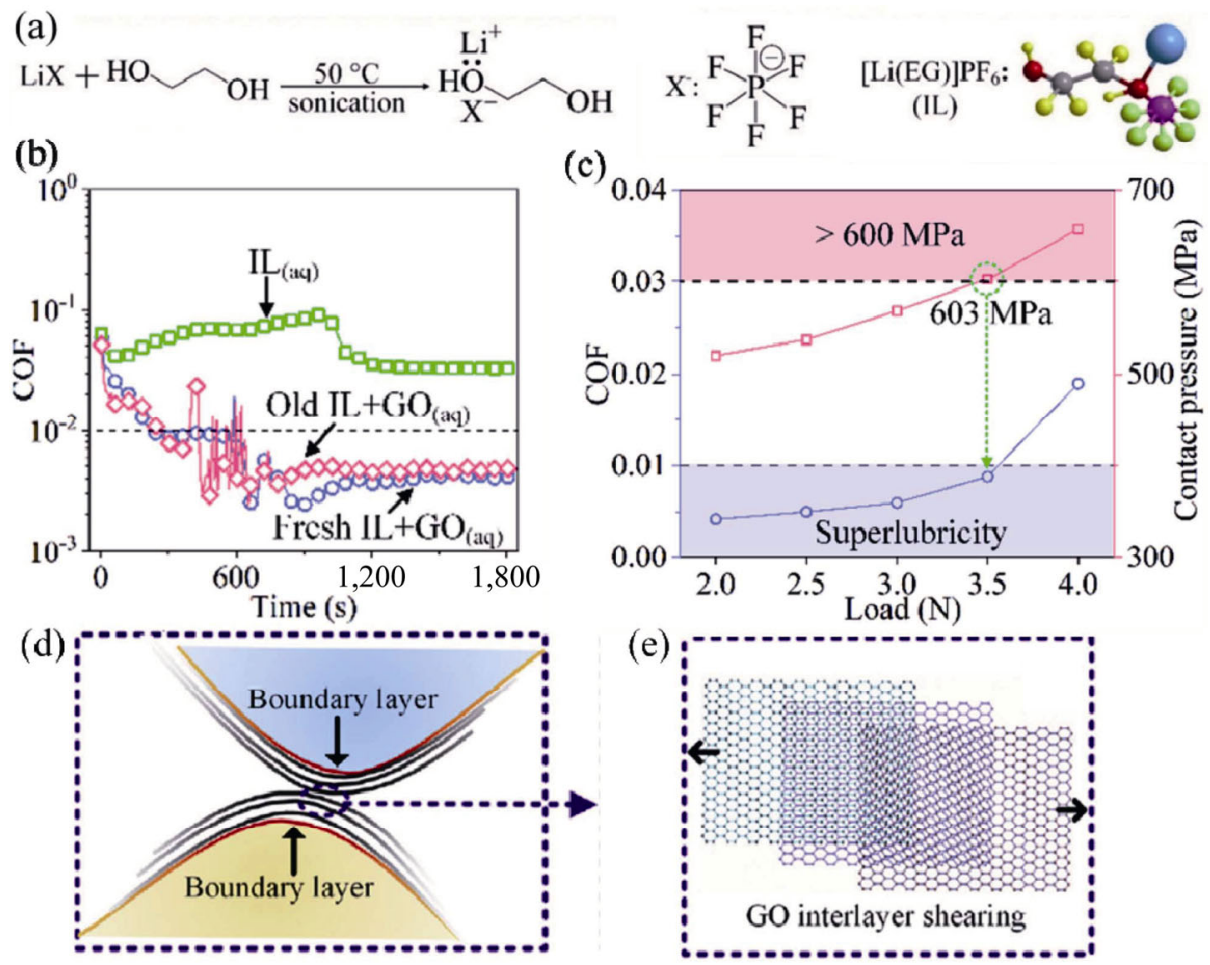

Fig. 7 (a) Illustration of $[\mathrm{Li}(\mathrm{EG})] \mathrm{PF}_{6}$ synthesis; $\mathrm{PF}_{6}^{-}$anion structure and schematic model of $[\mathrm{Li}(\mathrm{EG})] \mathrm{PF}$. (b) $\mathrm{COFs}$ of $30-\mu \mathrm{L}$ $\mathrm{IL}_{(\mathrm{aq})}$ and fresh and old $\mathrm{IL}+\mathrm{GO}_{(\mathrm{aq})}$. (c) COFs and contact pressures under various normal loads. Illustration for IL $+\mathrm{GO}_{(\mathrm{aq})}$ lubrication under extreme pressure: (d) Protection from adsorption layer of GO nanosheets and (e) shearing effect between GO nanosheets. Reproduced with permission from Ref. [70], (C) American Chemical Society 2019.

in Fig. 7(b), the COF of the IL aqueous solution varied from 0.04 to 0.1 and finally decreased to 0.033 , while the COF of the IL + GO aqueous solution decreased dramatically from 0.05 to 0.002 within $900 \mathrm{~s}$, which was considered the running-in period. Later, for the $2 \mathrm{~h}$ friction test, the COF varied slightly from 0.002 to 0.005 and finally stabilized at approximately 0.005 . Afterward, friction tests lubricated by IL + GO aqueous solution $(30 \mu \mathrm{L})$ under different normal loads were conducted, as shown in Fig. 7(c). When the normal load was applied from 2 to $4 \mathrm{~N}$, the corresponding contact pressure changed from 520 to $658 \mathrm{MPa}$, and the $\mathrm{COF}$ also increased. As the load increased from 2 to 3.5 $\mathrm{N}$ (applied pressure from 520 to $603 \mathrm{MPa}$ ), the lubrication systems were all maintained in the superlubricity region $(\mu<0.01)$, which implied a limit of contact pressure up to about $600 \mathrm{MPa}$ to achieve superlubricity with the IL + GO aqueous solution.

The lubrication mechanism including two parts (running-in period and superlubricity period) were proposed. During the initial running-in period, a tribochemical reaction took place such that a thin composite boundary layer containing phosphates was formed on a flat contact surface. This may cause an obvious decrease in contact pressure between the sliding solid surfaces. However, this was still unable to achieve superlubricity. As shown in Fig. 7(d), the asperities on the contact surfaces were adsorbed by GO nanosheets, which possessed ultralow shear stress between interlayers. This further reduced the friction to the superlubricity state, as shown in Fig. 7(e). In summary, an extreme pressure state was achieved with the formation of the boundary layer during the running-in period and also the adsorption layer of GO nanosheets with the properties of extreme pressure and weak interlayer shear stress. The combination of GO nanosheets and IL effectively improved the load-bearing capacity of liquid superlubricity to a level of $600 \mathrm{MPa}$, which contributed to the achievement of superlubricity under relatively high contact pressures. 


\section{$5 \quad$ LDH as lubricant additive}

\subsection{LDH additive in oil-based lubricant}

In 2017, Wang et al. [71] prepared three different nanosized $\mathrm{Ni}-\mathrm{Al} \mathrm{LDHs}$ by varying the hydrothermal reaction time during the microemulsification process. The layered structures and the 3D nanosize of the samples were confirmed by transmission electron microscopy (TEM) and AFM. As lubricant additives in base oil gas to liquids 8 (GTL8), their tribological properties under different loads were evaluated using a ball-on-disk tribometer. At a contact pressure of $2.16 \mathrm{GPa}$, the COF decreased by approximately $10 \%$, and the wear performance improved with the addition of nano-LDH. As shown in Fig. 8, the larger nanoplatelets (NiAl-24 h), rather than the small (NiAl-6 h), showed the best and stable tribological performance, mainly because of superior crystallinity, resulting in the formation of a tribofilm with more desirable mechanical properties during the sliding process. Thus, nano-LDHs with a simple preparation method and superior tribological properties as oilbased additives hold great potential for demanding industrial applications.

\subsection{LDH lubricant additive in water}

In 2016, Wang et al. [72] prepared NiAl-LDH nanoplatelets with few ordered layers using a microemulsion method and the schematic model in Fig. 9(a) showed the nanoplatelets stabilized via electrostatic interaction between polarized $\mathrm{OH}^{-}$ groups of $\mathrm{NiAl}-\mathrm{LDH}$ and $-\mathrm{NH}^{3+}$ head groups of oleylamine; $-\mathrm{OH}$ groups of assistant surfactant 1-butanol reduced the hydrophobicity of nanoplatelets. A stable translucent solution was obtained after directly dispersing them in water. During the friction tests, a lubricating layer was gradually formed under high contact pressure (initially approximately 1.5 GPa) because of the small size and excellent dispersion of nano-additives. The tribological performances of various lubricants are shown in Fig. 9(b). The lubricant sample with $0.5 \mathrm{wt} \% \mathrm{NiAl}-\mathrm{LDH}$ nanoplatelets exhibited superior lubricating performance. Compared to pure water, the $\mathrm{COF}$, wear scar diameter, depth, and width of wear track decreased by $83.1 \%, 43.2 \%$, $88.5 \%$, and $59.5 \%$, respectively. Owing to their layered structure with relatively weak interactions and high carrying capacity of laminates, the exfoliated nanosheets adsorb on the sliding solid surfaces during the friction process and prevent the direct collision of asperities

\subsection{Ultrathin LDH nanosheets in polyalkylene glycol aqueous solution: Adsorption enhance- ment}

In the GONFs-EDO superlubricity system, neither GONFs nor EDO could achieve robust superlubricity.
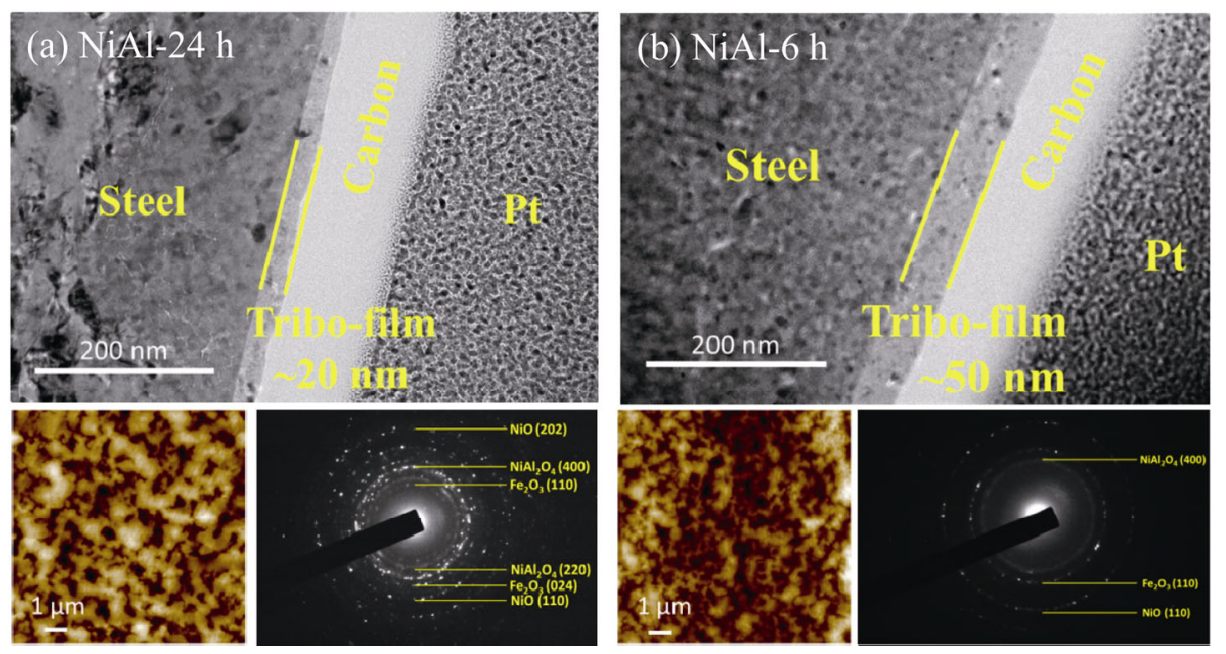

Fig. 8 Analysis of tribofilm formed on the wear track lubricated by (a) $1 \mathrm{wt} \% \mathrm{NiAl}-24 \mathrm{~h}$ and (b) $1 \mathrm{wt} \% \mathrm{NiAl}-6 \mathrm{~h}$ at $100 \mathrm{~N}$. Cross-sectional TEM image, surface topography by AFM, and diffraction pattern of tribofilm. Reproduced with permission from Ref. [71], (C) American Chemical Society 2017. 
(a)

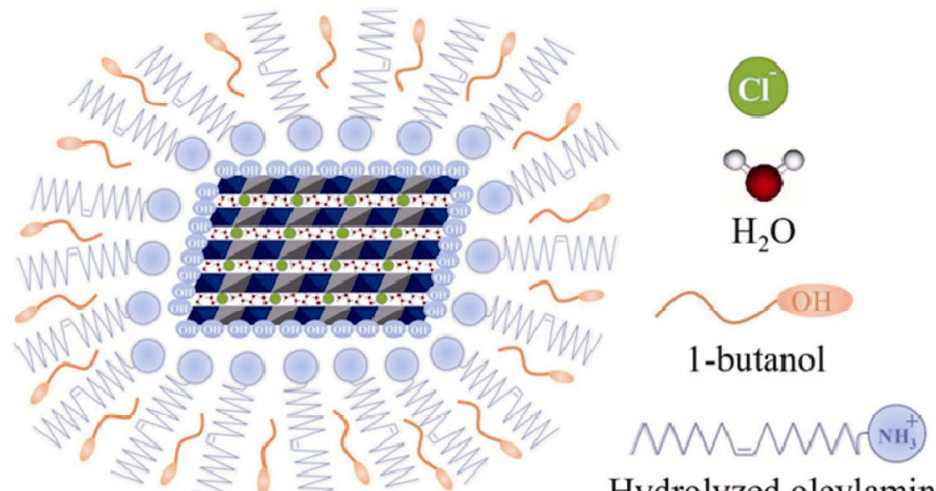

Hydrolyzed oleylamine
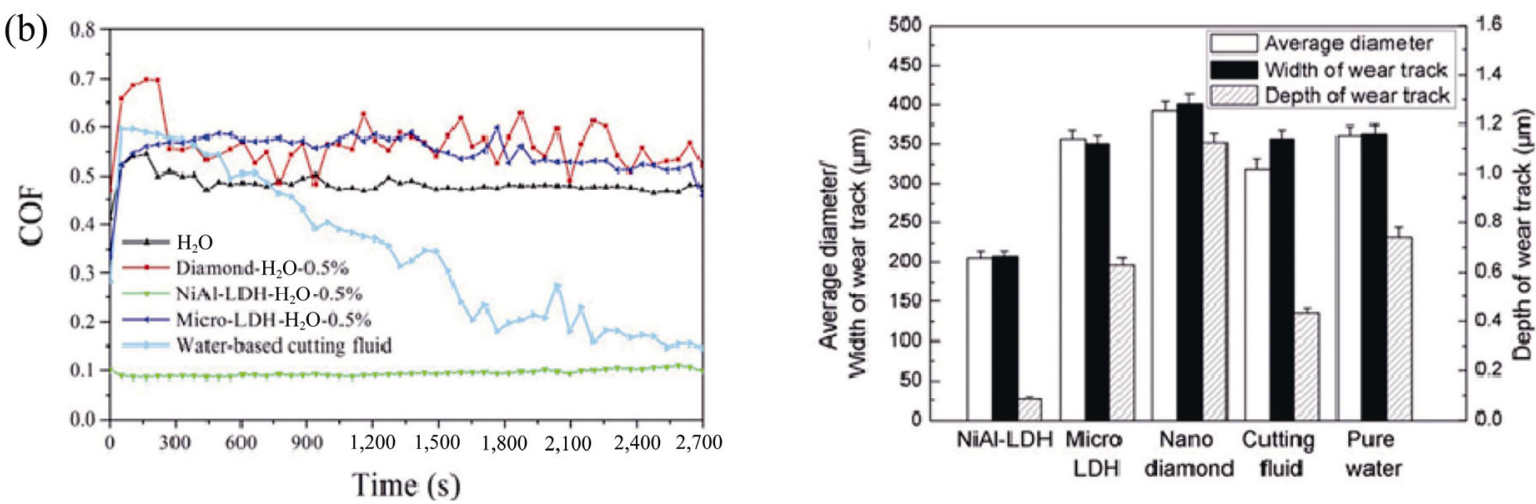

Fig. 9 (a) Schematic model of NiAl-LDH/OAm. (b) COF and wear condition of five lubricant samples, which contain diamond nanoparticles, NiAl-LDH nanoplatelets, LDH microplatelets, water-based cutting fluid, and pure water. Reproduced with permission from Ref. [72], (C) American Chemical Society 2016.

It was difficult to form a thick lubricating film with an aqueous EDO solution owing to the relatively small molecular weight and weak interaction of EDO molecules. Thus, increasing the molecular weight of water-soluble molecules is a good idea to improve the performance of superlubricity systems. In 2016, Wang et al. [40] achieved an ultralow COF (a minimum value of 0.0023 ) with a PAG aqueous solution in both the droplet state $(40 \mu \mathrm{L})$ and full immersion state in a reciprocating mode, as shown in Fig. 10(a).

As illustrated in Fig. 10(b), two key factors were suggested to achieve the state of superlubricity: A hydrated layer with low shearing strength and a suitable number of free water molecules. In the running-in process, decreasing the contact pressure was beneficial for the formation of elastohydrodynamic lubrication. The hydrated PAG chains and free water molecules provided ultralow shear strength when the two solid surfaces were sliding [73]. However, in this lubricating system, the running-in period is relatively long and is indispensable for achieving ultralow COFs. Moreover, the PAG aqueous solution

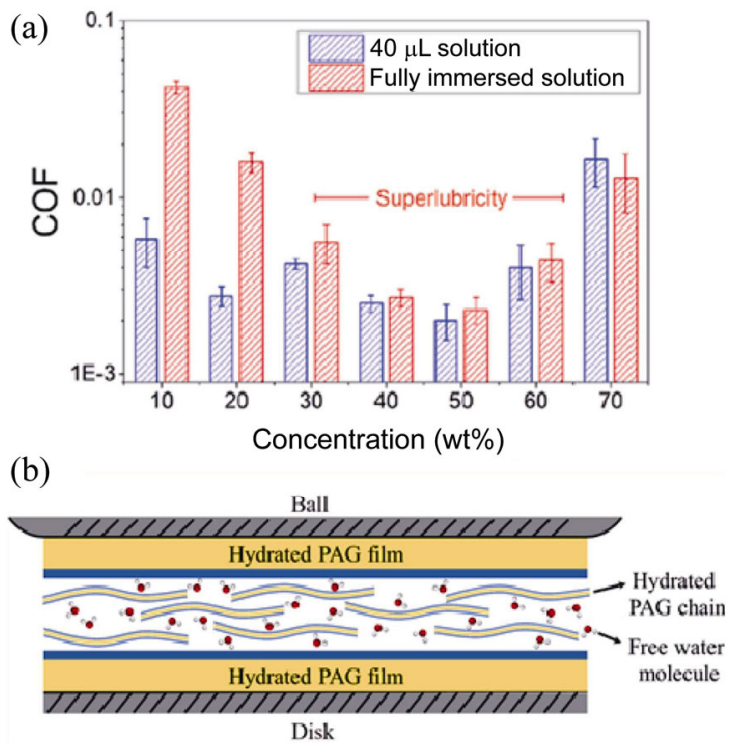

Fig. 10 (a) Final COF of $40 \mu \mathrm{L}$ and fully immersed PAG aqueous solutions (weight fraction from $10 \mathrm{wt} \%$ to $70 \mathrm{wt} \%$ ). Superlubricity is achieved over a range of concentrations from $30 \mathrm{wt} \%$ to $60 \mathrm{wt} \%$. (b) Schematic of the proposed lubrication model between two sliding surfaces. Reproduced with permission from Ref. [40], C WILEY-VCH Verlag GmbH \& Co. KGaA Weinheim 2016. 
decomposes and turns acidic after long storage, which may cause severe corrosion of contact surfaces and thereby limit its application. Since our studies showed that LDH was able to improve the lubrication properties and suppress acidification as a waterbased lubricant additive, it is promising to disperse nanosized LDHs in PAG aqueous solution to investigate whether superlubricity behavior can be further boosted.

In 2019, Wang et al. [74] synthesized two different nano-LDHs: ultrathin LDH nanosheets (ULDH-NS) and LDH nanoparticles (LDH-NP). As shown in Fig. 11(a), the ULDH-NS showed a lateral size of approximately $80 \mathrm{~nm}$ and a longitudinal size of approximately $1 \mathrm{~nm}$ (considered a single or double layer). The LDH-NP showed a lateral size of approximately $20 \mathrm{~nm}$ and a longitudinal size of approximately $10 \mathrm{~nm}$. Then, $0.5 \mathrm{wt} \% \mathrm{LDH}$ nanoadditives were dispersed in HB-400 PAG aqueous solution for tribological experiments. As shown in Fig. 11(b), the PAG aqueous solution took about $7,000 \mathrm{~s}$ to achieve superlubricity, in which the COF fluctuated during the running-in process with a wear scar of a diameter of approximately $400 \mu \mathrm{m}$, the contact pressure of $24.5 \mathrm{MPa}$, and surface roughness of Sa $3.5 \mathrm{~nm}$. With $0.5 \mathrm{wt} \%$ ULDH-NS additives, the running-in process (approximately $1,000 \mathrm{~s})$ was significantly shortened. Meanwhile, a wear scar with a diameter of approximately $200 \mu \mathrm{m}$, the contact pressure of $92.7 \mathrm{MPa}$, and surface roughness of Sa $3.9 \mathrm{~nm}$ was obtained. However, with the addition of $0.5 \mathrm{wt} \% \mathrm{LDH}-\mathrm{NP}$, the superlubricity state could not be achieved and the COF remained between 0.04 and 0.05 . It is understood that the ULDH-NS additives were easy to enter the contact interface during the friction process. However, a relatively large dimension of LDH-NPs might disturb the ultralow shear between the hydration layers, while the ULDH-NS additives (approximately $1 \mathrm{~nm}$ thick) were too thin to influence the continuity of the lubricant [40]. Next, $0.5 \mathrm{wt} \%$ ULDH-NS was added to water, and the COF was recorded under the same condition to investigate the lubrication mechanism of ULDH-NS as additives. Compared to the report on the wear resistance of LDH-NPs in water [72], the lubrication process of the ULDH-NS aqueous
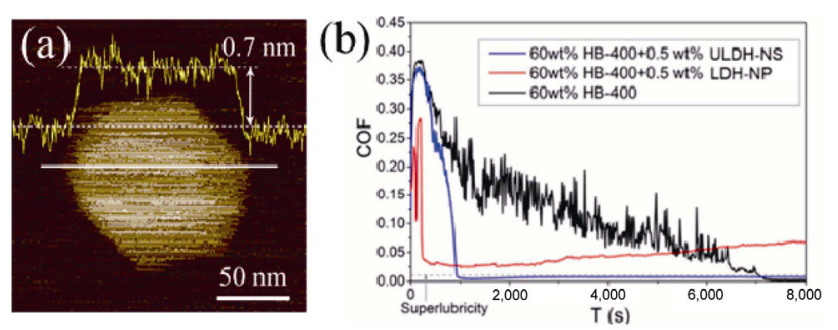

(c)
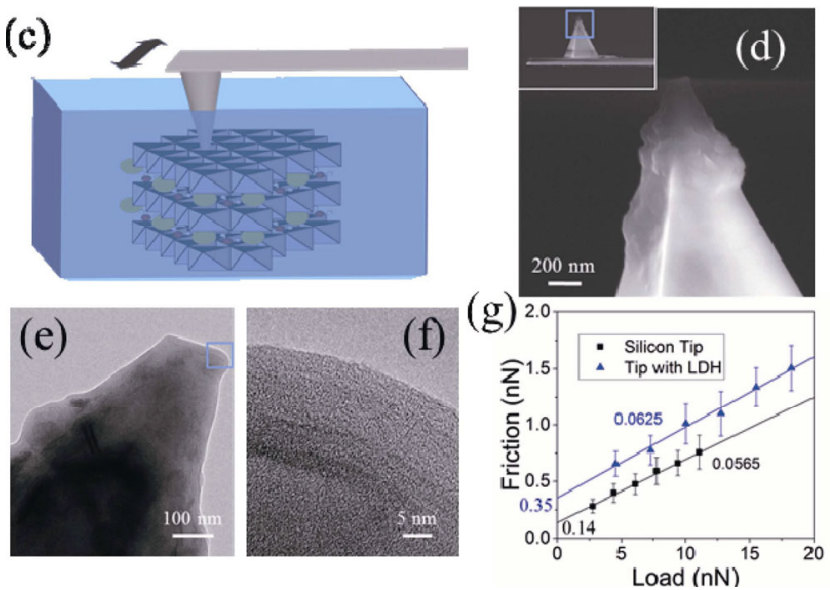

Fig. 11 (a) AFM image and cross-sectional profile of ULDH-NS. (b) COF of $60 \mathrm{wt} \%$ PAG aqueous solution and those with two $0.5 \mathrm{wt} \% \mathrm{LDH}$ additives: ULDH-NS and LDH-NP. (c) Schematic illustration of AFM friction test in water. (d) SEM image, (e) TEM image, and (f) HRTEM image of AFM tip with ULDH-NS. (g) Friction obtained between silicon tip vs. mica, and tip with $\mathrm{LDH}$ vs. mica. Reproduced with permission from Ref. [74], (C) American Chemical Society 2019.

solution was relatively stable, but the frictionreducing performance was not as significant. It was found that the surface roughness was approximately $68.5 \%$ lower than that lubricated by water, but the diameter was only $9 \%$ shorter. With an analysis of the solid contact surfaces, it was demonstrated that the physically adsorbed ULDH-NS enabled the sliding surfaces to be polished, and thus realizing quick progression to superlubricity.

Then, an AFM microscale friction test, as illustrated in Fig. 11(c), was conducted in lateral force measurement mode to evaluate the interactions between asperity peaks and stacked ULDH-NS additives in water. With continuous scanning, it was found that the stacked ULDH-NS gradually exfoliated with the removal thickness of one laminate $(0.6-0.7 \mathrm{~nm})$ due to the relatively weak interaction between the laminates. The morphology of the tip is shown in Fig. 11(d) after several 
scanning cycles using an AFM tip. The TEM image in Fig. 11(e) and energy dispersive spectrometer (EDS) analysis confirmed the adsorption of LDH nanosheets. The HRTEM image in Fig. 11(f) shows that the ULDH-NS stacking process was similar to the condition of macroscopic experiment. As shown in Fig. 11(g), the COF (approximately 0.0625) obtained by the tip with LDH nanosheets was quite close to the COF (approximately 0.0565) obtained by the fresh silicon tip, but the adhesive force $(0.35 \mathrm{nN})$ was significantly improved, which may contribute to the adsorption of PAG molecules on the solid surfaces during sliding process. Generally, adhesion forces consist of various forces such as electrostatic, van der Waals, and capillary. In a liquid environment, the capillary force $\left(F_{\mathrm{c}}\right)$ plays a crucial role and can be evaluated using the formula $F_{\mathrm{c}}=4 \pi \sigma R \cos \theta$, where $\sigma$ is the surface tension of water, $R$ is the radius of the tip, and $\theta$ is the contact angle of water [75]. According to the formula, the force of adhesion was mainly determined by the wettability of the contact surface with the dropped liquid. Many hydroxyl groups and a small amount of ethylene glycol molecules on the surface of the LDH nanosheets enabled the solid surfaces to be extremely hydrophilic, and their adhesion force was improved. Thus, the favorable conditions of the PAG aqueous solution for shortening the running-in process were provided by this adsorption layer. This can prevent violent collisions to shorten the running-in time (within $1,000 \mathrm{~s}$ ) by $85 \%$ and improve the load-bearing capacity (approximately 92.7 MPa) with the enhanced adsorption of ULDH-NS.

\section{Discussion}

In earlier related studies [76-78], it was widely reported that a long time sliding process of mated ceramics (e.g., $\mathrm{Si}_{3} \mathrm{~N}_{4}-\mathrm{Al}_{2} \mathrm{O}_{3}$ ) in water would lead to the occurrence of tribocorrosion, where an ultralow COF $(<0.03)$ could finally be obtained. After the friction test, a hydrated thin film of silicon oxides on sliding solid surfaces was detected. The restricted conditions for achieving ultralow friction were extremely low contact pressure $(<10 \mathrm{MPa})$, very smooth surface $(<10 \mathrm{~nm})$, and high relative velocity (approximately $1.0 \mathrm{~m} / \mathrm{s}$ ). In the ceramic-water lubrication system, the rate of the tribochemical reaction is relatively slow, and the equivalent viscosity of the small amount of silica sol formed is too low to completely prevent direct collisions of asperities and to bear high contact pressure. However, the sliding process under strong acidic conditions can accelerate the violent occurrence of tribochemical reactions in the superlubricity system of phosphoric acid solution [30]. With BP-OH additives uniformly dispersed in water, a similar composite of phosphoric acid is produced between sliding ceramic surfaces and the aqueous solution [67]. It was demonstrated that the tribochemical reaction occurring with $\mathrm{BP}-$ $\mathrm{OH}$ additives effectively reduced the surface roughness and contact pressure, formed repulsive electrostatic interactions, increased the equivalent viscosity of the lubricant to strengthen the hydrodynamic effect, and thus bore a high load in the state of superlubricity.

During the sliding process, the adsorbed 2D nano-additives (e.g., GO nanosheets and LDHs) might gather on the solid surfaces to form a much thicker protective layer as compared to the original materials. It is considered that the wear condition is commonly observed in the contact region of approaching asperities during the running-in period. Thus, the direct contact of sliding solid surfaces can be physically prevented by the adsorbed layer, and the sliding interaction determined by the interface between laminates. This may lead to extremely low wear rates and an obvious reduction of friction in boundary lubrication [72, 79-81]. For example, the COF value of the sliding $\mathrm{Si}_{3} \mathrm{~N}_{4}-\mathrm{SiO}_{2}$ interface in water usually exceeds 0.6 , while the COF values of the interface between GO or LDH nanosheets are in the range of $0.02-0.1$ in macroscale friction process [73, 82-84]. However, superlubricity cannot be achieved with the adsorbed 2D nano-additives alone. Present superlubricity systems are mostly achieved in an aqueous solution and a lubrication state, where only a small amount of nano-additives in water is commonly recognized as boundary lubrication. An appropriate amount of water-soluble molecules (such as ethaneidol, polyhydroxy alcohol, and PAGs) added to water could effectively increase the lubricant film thickness to reduce collision 
probability between asperities while weakening the interactions between themselves to decrease shear strength of the lubricant fluid. In addition, the surface of superlubricity additives is usually covered with a large quantity of hydrophilic functional groups, and thus the sliding solid surfaces become extremely hydrophilic and their adhesive force increases significantly with the adsorption of many nanosheets on the contact surfaces. In these superlubricity systems, the increasing adhesive force contributes to the adsorption of water-soluble molecules on the sliding solid surfaces, so the violent collisions are effectively prevented during the friction process, which accelerates the achievement of superlubricity. As a result, the synergistic effects of physical protection and adsorption enhancement, caused by the combination of $2 \mathrm{D}$ nano-additives and water-soluble molecules, greatly contribute to the improvement of tribological properties in superlubricity systems.

As for superlubricity achieved with ionic liquids, the wear resistance can be greatly improved, and accordingly, excellent extreme pressure is obtained. Notably, a tribochemical reaction occurs during the sliding process in which the anions in ionic liquids such as $\mathrm{PF}_{6}^{-}, \mathrm{BF}_{4}^{-}$, and $\mathrm{NTf}_{2}^{-}$react with water to produce phosphates [85], borides [86], and sulfides [87] on the worn surface, respectively [36, 88]. Owing to the excellent extreme pressure and anti-wear properties of phosphates, the tribochemical layer formed by $\mathrm{PF}_{6}^{-}$exhibits the best lubricating performance [89]. On the other hand, the cations in ionic liquids such as $\mathrm{Li}^{+}, \mathrm{Na}^{+}$, and $\mathrm{K}^{+}$possess quite different hydrated radii and hydration energies.
Hence, the as-formed hydration layer and hydration repulsion, caused by the adsorbed cations on the negatively charged solid surfaces, may directly affect the tribological properties [90]. Since hydration of $\mathrm{Li}^{+}$is much stronger than those of $\mathrm{Na}^{+}$and $\mathrm{K}^{+}$, extremely low shearing resistance and hydration repulsion is provided with a hydration layer on sliding solid surfaces $[75,91]$. Both the occurrence of tribochemical reaction with anions and the excellent ability to hydrate by cations in ionic liquids can further improve the wear resistance of liquid superlubricant, and thereby increasing the load-bearing capacity to a high level for industrial application.

Recently, Liu et al. [92] investigated three graphenederived nanoflakes of different hydrophilicity with the lubrication of glycerol solution. Initially, pristine graphene (PG), fluorinated graphene (FG), and GO nanoflakes were directly deposited on the substrate $\left(\mathrm{SiO}_{2}\right)$. The aqueous solution of glycerol was dropped between two sliding solid surfaces for friction test. The results showed the hydrophobic PG nanoflakes exhibited the best lubrication performance and a robust superlubricity with COF of approximately 0.004. Given the fact that GO nanoflakes showed the best while FG nanoflakes showed the worst hydrophilicity, hydrophilic properties had little effect on the lubrication performance in this lubrication system. As shown in Fig. 12, the excellent performance of PG was mainly attributed to a tribofilm composed of graphene nanoflakes formed in the contact zone, while the functional group of GO caused relatively large interaction force between nanoflakes. However, as for hydrophobic PG nanoflakes, it is still a great

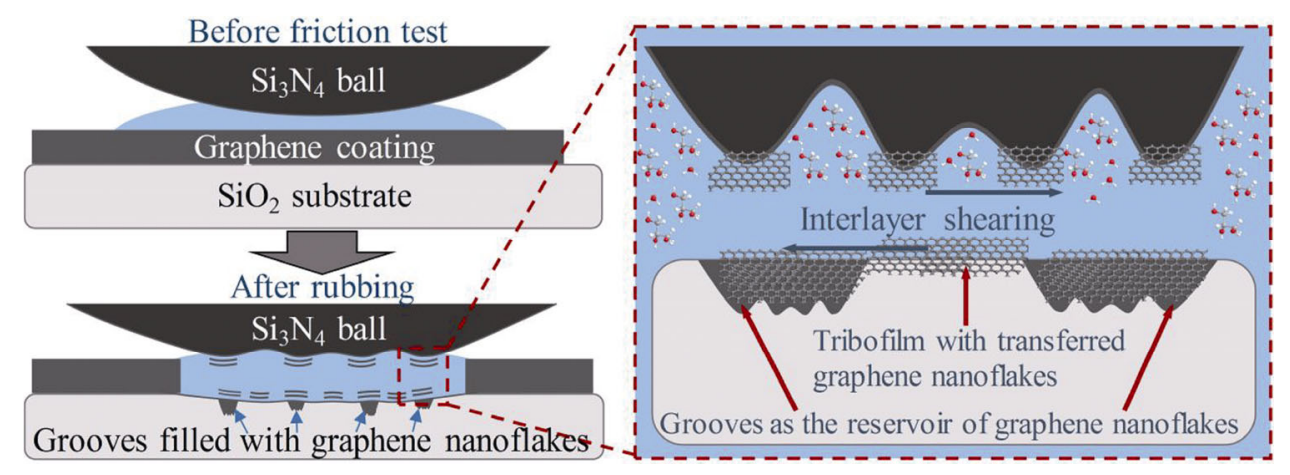

Fig. 12 Lubrication model of hydrophobic pristine graphene nanoflakes and the glycerol aqueous solution. Reproduced with permission from Ref. [92], (C) American Chemical Society 2020. 
challenge to solve its dispersion problem as lubricant additives in the future.

\section{Summary}

This paper provided a review of the studies on the synergistic effect of 2D solid materials and waterbased lubricants in the field of liquid superlubricity. Suitable 2D nanomaterials as lubricant additives can prevent severe wear on solid surfaces and improve the tribological properties. According to previous studies on liquid superlubricity, there are still many aspects (e.g., low load-bearing pressure, dependence on hydrogen ions, and relatively long running-in processes) that need to be further explored and improved.

In this study, various 2D nanomaterials including $\mathrm{BP}, \mathrm{LDH}$, and GO were prepared, surface modified, and well dispersed in water-based lubricants for optimizing the applied conditions of superlubricity. Until now, liquid superlubricity has been increasingly controllable and adjustable. As shown in Table 2, the load-bearing capacity was effectively improved to $600 \mathrm{MPa}$ and the running-in time was shortened to $1,000 \mathrm{~s}$.

This review focused on the latest reports on the combination of 2D solid materials and water-based lubricants. It provides the guidance for utilizing liquid superlubricity for potential applications. However, to meet the harsh conditions of practical operation in mechanical systems, corrosion is still a challenge, and the load capacity of water-based lubricant systems must be further improved in the future. In addition, it is also difficult to achieve superlubricity in oil-based lubricants due to their

Table 2 Liquid superlubricity systems with different sliding solid surfaces, liquid lubricants, nano-additives, final contact pressure $(\mathrm{MPa})$, and running-in period (s) in superlubricity state.

\begin{tabular}{cccc}
\hline Solid surfaces & $\begin{array}{c}\text { Lubricants }+ \\
\text { additives }\end{array}$ & $\begin{array}{c}\text { Contact } \\
\text { pressure } \\
(\mathrm{MPa})\end{array}$ & $\begin{array}{c}\text { Running-in } \\
\text { period (s) }\end{array}$ \\
\hline $\mathrm{Si}_{3} \mathrm{~N}_{4} / \mathrm{SiO}_{2}$ & Water $+\mathrm{BP}-\mathrm{OH}$ & 96 & $\sim 3,600$ \\
$\mathrm{Si}_{3} \mathrm{~N}_{4} / \mathrm{SiO}_{2}$ & $\begin{array}{c}\text { Ethanediol }+ \\
\text { GONFs }\end{array}$ & 111 & $\sim 600$ \\
$\mathrm{Si}_{3} \mathrm{~N}_{4} / \mathrm{sapphire}$ & $\begin{array}{c}\mathrm{IL}_{(\mathrm{aq})}+\mathrm{GO} \\
\mathrm{PAG}_{(\mathrm{aq})}+\end{array}$ & 600 & $<900$ \\
$\mathrm{Si}_{3} \mathrm{~N}_{4} / \mathrm{Al}_{2} \mathrm{O}_{3}$ & $\mathrm{ULDH}-\mathrm{NS}$ & 93 & $<1,000$ \\
\hline
\end{tabular}

relatively strong intermolecular interaction and shear forces. Thus, more lubricant systems containing new liquid lubricants and nano-additives with superlubricity properties also remain to be investigated.

\section{Acknowledgements}

This study was financially supported by the National Natural Science Foundation of China (51905294, 51527901, and 51875303), the China Postdoc Innovation Talent Support Program (BX20180168), and the China Postdoctoral Science Foundation (2019M650654). The authors thank Dr. Jinjin LI for his valuable suggestions.

Open Access This article is licensed under a Creative Commons Attribution 4.0 International License, which permits use, sharing, adaptation, distribution and reproduction in any medium or format, as long as you give appropriate credit to the original author(s) and the source, provide a link to the Creative Commons licence, and indicate if changes were made.

The images or other third party material in this article are included in the article's Creative Commons licence, unless indicated otherwise in a credit line to the material. If material is not included in the article's Creative Commons licence and your intended use is not permitted by statutory regulation or exceeds the permitted use, you will need to obtain permission directly from the copyright holder.

To view a copy of this licence, visit http://creativecommons.org/licenses/by/4.0/.

\section{References}

[1] Perry S S, Tysoe W T. Frontiers of fundamental tribological research. Tribol Lett 19(3): 151-161 (2005)

[2] Wen S Z, Huang P. Principles of Tribology. New York (USA): John Wiley \& Sons, 2012.

[3] Holmberg K, Erdemir A. Influence of tribology on global energy consumption, costs and emissions. Friction 5(3): 263-284 (2017)

[4] Hirano M, Shinjo K. Atomistic locking and friction. Phys Rev B 41(17): 11837-11851 (1990)

[5] Erdemir A, Martin J. Superlubricity. New York (USA): Elsevier, 2007. 
[6] Xu J, Li J J. New achievements in superlubricity from international workshop on superlubricity: Fundamental and applications. Friction 3(4): 344-351 (2015)

[7] Dienwiebel M, Verhoeven G S, Pradeep N, Frenken J W M, Heimberg J A, Zandbergen H W. Superlubricity of graphite. Phys Rev Lett 92(12): 126101 (2004)

[8] Liu Z, Yang J R, Grey F, Liu J Z, Liu Y L, Wang Y B, Yang Y L, Cheng Y, Zheng Q S. Observation of microscale superlubricity in graphite. Phys Rev Lett 108(20): 205503 (2012)

[9] Hu Y Z, Ma T B, Wang H. Energy dissipation in atomicscale friction. Friction 1(1): 24-40 (2013)

[10] Hirano M. Atomistics of superlubricity. Friction 2(2): 95-105 (2014)

[11] Zheng Q S, Liu Z. Experimental advances in superlubricity. Friction 2(2): 182-192 (2014)

[12] Berman D, Deshmukh S A, Sankaranarayanan S K R S, Erdemir A, Sumant A V. Macroscale superlubricity enabled by graphene nanoscroll formation. Science 348(6239): 1118-1122 (2015)

[13] Li H, Wang J H, Gao S, Chen Q, Peng L M, Liu K H, Wei X L. Superlubricity between $\mathrm{MoS}_{2}$ monolayers. $A d v$ Mater 29(27): 1701474 (2017)

[14] Liu S W, Wang H P, Xu Q, Ma T B, Yu G, Zhang C H, Geng D C, Yu Z W, Zhang S G, Wang W Z, et al. Robust microscale superlubricity under high contact pressure enabled by graphene-coated microsphere. Nat Commun 8: 14029 (2017)

[15] Berman D, Erdemir A, Sumant A V. Approaches for achieving superlubricity in two-dimensional materials. ACS Nano 12(3): 2122-2137 (2018)

[16] Liu Y M, Song A S, Xu Z, Zong R L, Zhang J, Yang W $\mathrm{Y}$, Wang $\mathrm{R}, \mathrm{Hu} \mathrm{Y} \mathrm{Z}$, Luo J B, Ma T B. Interlayer friction and superlubricity in single-crystalline contact enabled by two-dimensional flake-wrapped atomic force microscope tips. ACS Nano 12(8): 7638-7646 (2018)

[17] Chen X C, Li J J. Superlubricity of carbon nanostructures. Carbon 158: 1-23 (2020)

[18] $\mathrm{Xu} \mathrm{J} \mathrm{G,} \mathrm{Kato} \mathrm{K.} \mathrm{Formation} \mathrm{of} \mathrm{tribochemical} \mathrm{layer} \mathrm{of}$ ceramics sliding in water and its role for low friction. Wear 245(1-2): 61-75 (2000)

[19] Chen M, Kato K, Adachi K. Friction and wear of selfmated $\mathrm{SiC}$ and $\mathrm{Si}_{3} \mathrm{~N}_{4}$ sliding in water. Wear 250(1-12): 246-255 (2001)

[20] Wong H C, Umehara N, Kato K. The effect of surface roughness on friction of ceramics sliding in water. Wear 218(2): 237-243 (1998)

[21] Matsuda M, Kato K, Hashimoto A. Friction and wear properties of silicon carbide in water from different sources. Tribol Lett 43(1): 33-41 (2011)

[22] Klein J, Luckham P. Forces between two adsorbed polyethylene oxide layers immersed in a good aqueous solvent. Nature 300(5891): 429-431 (1982)

[23] Klein J, Fletcher D, Fetters L J. Diffusional behaviour of entangled star polymers. Nature 304(5926): 526-527 (1983)

[24] Klein J, Kumacheva E, Mahalu D, Perahia D, Fetters L J. Reduction of frictional forces between solid surfaces bearing polymer brushes. Nature 370(6491): 634-636 (1994)

[25] Klein J, Raviv U, Perkin S, Kampf N, Chai L, Giasson S. Fluidity of water and of hydrated ions confined between solid surfaces to molecularly thin films. $J$ Phys: Condens Matter 16(45): S5437-S5448 (2004)

[26] Li J J, Zhang C H, Sun L, Lu X C, Luo J B. Tribochemistry and superlubricity induced by hydrogen ions. Langmuir 28(45): 15816-15823 (2012)

[27] Li J J, Zhang C H, Luo J B. Superlubricity achieved with mixtures of polyhydroxy alcohols and acids. Langmuir 29(17): 5239-5245 (2013)

[28] Li J J, Zhang C H, Ma L R, Liu Y H, Luo J B. Superlubricity achieved with mixtures of acids and glycerol. Langmuir 29(1): 271-275 (2013)

[29] Li J J, Zhang C H, Deng M M, Luo J B. Reduction of friction stress of ethylene glycol by attached hydrogen ions. Sci Rep 4: 7226 (2014)

[30] Li J J, Zhang C H, Luo J B. Superlubricity behavior with phosphoric acid-water network induced by rubbing Langmuir 27(15): 9413-9417 (2011)

[31] Sun L, Zhang C H, Li J J, Liu Y H, Luo J B. Superlubricity of $\mathrm{Si}_{3} \mathrm{~N}_{4}$ sliding against $\mathrm{SiO}_{2}$ under linear contact conditions in phosphoric acid solutions. Sci China-Technol Sci 56(7): 1678-1684 (2013)

[32] Deng M M, Zhang C H, Li J J, Ma L R, Luo J B. Hydrodynamic effect on the superlubricity of phosphoric acid between ceramic and sapphire. Friction 2(2): 173181 (2014)

[33] Li J J, Zhang C H, Deng M M, Luo J B. Investigations of the superlubricity of sapphire against ruby under phosphoric acid lubrication. Friction 2(2): 164-172 (2014)

[34] Ma W, Gong Z B, Gao K X, Qiang L, Zhang J Y, Yu S R. Superlubricity achieved by carbon quantum dots in ionic liquid. Mater Lett 195: 220-223 (2017)

[35] Ge X Y, Li J J, Zhang C H, Wang Z N, Luo J B. Superlubricity of 1-Ethyl-3-methylimidazolium trifluoro methanesulfonate ionic liquid induced by tribochemical reactions. Langmuir 34(18): 5245-5252 (2018)

[36] Ge X Y, Li J J, Zhang C H, Liu Y H, Luo J B. Superlubricity and antiwear properties of in situ-formed ionic liquids at ceramic interfaces induced by tribochemical reactions. ACS Appl Mater Interfaces 11(6): 6568-6574 (2019)

[37] Han T Y, Zhang C H, Luo J B. Macroscale super- 
lubricity enabled by hydrated alkali metal ions. Langmuir 34(38): 11281-11291 (2018)

[38] Ge X Y, Li J J, Zhang C H, Luo J B. Liquid superlubricity of polyethylene glycol aqueous solution achieved with boric acid additive. Langmuir 34(12): 3578-3587 (2018)

[39] Zhang C X, Liu Z F, Liu Y H, Ren J, Cheng Q, Yang C B, Cai L G. Novel tribological stability of the superlubricity poly (Vinylphosphonic Acid) (PVPA) coatings on $\mathrm{Ti}_{6} \mathrm{Al}_{4} \mathrm{~V}$ : Velocity and load independence. Appl Surf Sci 392: 19-26 (2017)

[40] Wang H D, Liu Y H, Li J J, Luo J B. Investigation of superlubricity achieved by polyalkylene glycol aqueous solutions. Adv Mater Interfaces 3(19): 1600531 (2016)

[41] Chen Z, Liu Y H, Zhang S H, Luo J B. Controllable superlubricity of glycerol solution via environment humidity. Langmuir 29(38): 11924-11930 (2013)

[42] Li K, Zhang S M, Liu D S, Amann T, Zhang C H, Yuan C Q, Luo J B. Superlubricity of 1, 3-diketone based on autonomous viscosity control at various velocities. Tribol Int 126: 127-132 (2018)

[43] Ge X Y, Li J J, Luo J B. Macroscale superlubricity achieved with various liquid molecules: A review. Front Mech Eng 5: 2 (2019)

[44] Chen Z, Liu Y H, Luo J B. Superlubricity of nanodiamonds glycerol colloidal solution between steel surfaces. Colloids Surf A: Physicochem Eng Aspects 489: 400-406 (2016)

[45] Tan C L, Cao X H, Wu X J, He Q Y, Yang J, Zhang X, Chen J Z, Zhao W, Han S K, et al. Recent advances in ultrathin two-dimensional nanomaterials. Chem Rev 117(9): 6225-6331 (2017)

[46] Dietzel D, Schwarz U D, Schirmeisen A. Nanotribological studies using nanoparticle manipulation: Principles and application to structural lubricity. Friction 2(2): 114139 (2014)

[47] Li J J, Li J F, Luo J B. Superlubricity of graphite sliding against graphene nanoflake under ultrahigh contact pressure. Adv Sci 5(11): 1800810 (2018)

[48] Li J J, Gao T Y, Luo J B. Superlubricity of graphite induced by multiple transferred graphene nanoflakes. Adv Sci 5(3): 1700616 (2018)

[49] Li H, Wu J, Yin Z Y, Zhang H. Preparation and applications of mechanically exfoliated single-layer and multilayer $\mathrm{MoS}_{2}$ and $\mathrm{WSe}_{2}$ nanosheets. Acc Chem Res 47(4): 1067-1075 (2014)

[50] Wang H D, Liu Y H, Guo F M, Sheng H P, Xia K L, Liu W R, Wen J G, Shi Y J, Erdemir A, Luo J B. Catalytically active oil-based lubricant additives enabled by calcining Ni-Al layered double hydroxides. J Phys Chem Lett 11(1): 113-120 (2020)

[51] Peng Y, Li Y S, Ban Y J, Jin H, Jiao W M, Liu X L,
Yang W S. Metal-organic framework nanosheets as building blocks for molecular sieving membranes. Science 346(6215): 1356-1359 (2014)

[52] Colson J W, Woll A R, Mukherjee A, Levendorf M P, Spitler E L, Shields V B, Spencer M G, Park J, Dichtel W R. Oriented 2D covalent organic framework thin films on single-layer graphene. Science 332(6026): 228-231 (2011)

[53] Zhang J S, Chen Y, Wang X C. Two-dimensional covalent carbon nitride nanosheets: Synthesis, functionalization, and applications. Energy Environ Sci 8(11): 3092-3108 (2015)

[54] Zhi C Y, Bando Y, Tang C C, Kuwahara H, Golberg D. Large-scale fabrication of boron nitride nanosheets and their utilization in polymeric composites with improved thermal and mechanical properties. Adv Mater 21(28): 2889-2893 (2009)

[55] Chen Z, Liu X W, Liu Y H, Gunsel S, Luo J B. Ultrathin $\mathrm{MoS}_{2}$ nanosheets with superior extreme pressure property as boundary lubricants. Sci Rep 5: 12869 (2015)

[56] Chen Z, Liu Y H, Gunsel S, Luo J B. Mechanism of antiwear property under high pressure of synthetic oil-soluble ultrathin $\mathrm{MoS}_{2}$ sheets as lubricant additives. Langmuir 34(4): 1635-1644 (2018)

[57] Zhao J, He Y Y, Wang Y F, Wang W, Yan L, Luo J B. An investigation on the tribological properties of multilayer graphene and $\mathrm{MoS}_{2}$ nanosheets as additives used in hydraulic applications. Tribol Int 97: 14-20 (2016)

[58] Zhao J, Mao J Y, Li Y R, He Y Y, Luo J B. Frictioninduced nano-structural evolution of graphene as a lubrication additive. Appl Surf Sci 434: 21-27 (2018)

[59] Meng Y, Su F H, Chen Y Z. A novel nanomaterial of graphene oxide dotted with $\mathrm{Ni}$ nanoparticles produced by supercritical $\mathrm{CO}_{2}$ - assisted deposition for reducing friction and wear. ACS Appl Mater Interfaces 7(21): 11604-11612 (2015)

[60] Meng Y, Su F H, Chen Y Z. Synthesis of nano-Cu/ graphene oxide composites by supercritical $\mathrm{CO}_{2}$-assisted deposition as a novel material for reducing friction and wear. Chem Eng J 281: 11-19 (2015)

[61] Meng Y, Su F H, Chen Y Z. Au/Graphene oxide nanocomposite synthesized in supercritical $\mathrm{CO}_{2}$ fluid as energy efficient lubricant additive. ACS Appl Mater Interfaces 9(45): 39549-39559 (2017)

[62] Hou X, Yang C Z, He J, Li Z W, Zhang Z J. Preparation and tribological properties of lanthanum trifluoride nanoparticles-decorated graphene oxide nanosheets. Ind Eng Chem Res 54(17): 4773-4780 (2015)

[63] Du S N, Sun J L, Wu P. Preparation, characterization and lubrication performances of graphene oxide- $\mathrm{TiO}_{2}$ nanofluid in rolling strips. Carbon 140: 338-351 (2018)

[64] Wu J, Mu L W, Zhu J H, Feng X, Lu X H, Larsson R, 
Shi Y J. Synthesis of hollow fullerene-like molybdenum disulfide/reduced graphene oxide nanocomposites with excellent lubricating properties. Carbon 134: 423-430 (2018)

[65] Zhang L L, Pu J B, Wang L P, Xue Q J. Synergistic effect of hybrid carbon nanotube-graphene oxide as nanoadditive enhancing the frictional properties of ionic liquids in high vacuum. ACS Appl Mater Interfaces 7(16): 8592-8600 (2015)

[66] Wang W, Xie G X, Luo J B. Black phosphorus as a new lubricant. Friction 6(1): 116-142 (2018)

[67] Wang W, Xie G X, Luo J B. Superlubricity of black phosphorus as lubricant additive. ACS Appl Mater Interfaces 10(49): 43203-43210 (2018)

[68] Kinoshita H, Nishina Y, Alias A A, Fujii M. Tribological properties of monolayer graphene oxide sheets as water-based lubricant additives. Carbon 66: 720-723 (2014)

[69] Ge X Y, Li J J, Luo R, Zhang C H, Luo J B. Macroscale superlubricity enabled by the synergy effect of graphene-oxide nanoflakes and ethanediol. ACS Appl Mater Interfaces 10(47): 40863-40870 (2018)

[70] Ge X Y, Li J J, Wang H D, Zhang C H, Liu Y H, Luo J B. Macroscale superlubricity under extreme pressure enabled by the combination of graphene-oxide nanosheets with ionic liquid. Carbon 151: 76-83 (2019)

[71] Wang H D, Liu Y H, Liu W R, Wang R, Wen J G, Sheng H P, Peng J F, Erdemir A, Luo J B. Tribological behavior of NiAl-layered double hydroxide nanoplatelets as oil-based lubricant additives. ACS Appl Mater Interfaces 9(36): 30891-30899 (2017)

[72] Wang H D, Liu Y H, Chen Z, Wu B B, Xu S L, Luo J B. Layered double hydroxide nanoplatelets with excellent tribological properties under high contact pressure as water-based lubricant additives. Sci Rep 6(1): 22748 (2016)

[73] Liu W R, Wang H D, Liu Y H, Li J J, Erdemir A, Luo J B. Mechanism of superlubricity conversion with polyalkylene glycol aqueous solutions. Langmuir 35(36): 11784-11790 (2019)

[74] Wang H D, Liu Y H, Liu W R, Liu Y M, Wang K P, Li J J, Ma T B, Eryilmaz O L, Shi Y J, Erdemir A, et al. Superlubricity of polyalkylene glycol aqueous solutions enabled by ultrathin layered double hydroxide nanosheets. ACS Appl Mater Interfaces 11(22): 20249-20256 (2019)

[75] Israelachvili J N. Intermolecular and Surface Forces. 3rd edn. London (UK): Academic Press, 2011.

[76] Xu J G, Kato K, Hirayama T. The transition of wear mode during the running-in process of silicon nitride sliding in water. Wear 205(1-2): 55-63 (1997)

[77] Wong H C, Umehara N, Kato K. Frictional characteristics of ceramics under water-lubricated conditions. Tribol Lett
5(4): 303-308 (1998)

[78] Ferreira V, Yoshimura H N, Sinatora A. Ultra-low friction coefficient in alumina-silicon nitride pair lubricated with water. Wear 296(1-2): 656-659 (2012)

[79] Pamies R, Avilés M D, Arias-Pardilla J, Espinosa T, Carrión F J, Sanes J, Bermúdez M D. Antiwear performance of ionic liquid+graphene dispersions with anomalous viscosity-temperature behavior. Tribol Int 122: 200-209 (2018)

[80] Tapasztó O, Balko J, Puchy V, Kun P, Dobrik G, Fogarassy Z, Horváth Z E, Dusza J, Balázsi K, Balázsi C, et al. Highly wear-resistant and low-friction $\mathrm{Si}_{3} \mathrm{~N}_{4}$ composites by addition of graphene nanoplatelets approaching the 2D limit. Sci Rep 7: 10087 (2017)

[81] Shang W J, Cai T, Zhang Y X, Liu D, Liu S G. Facile one pot pyrolysis synthesis of carbon quantum dots and graphene oxide nanomaterials: All carbon hybrids as eco-environmental lubricants for low friction and remarkable wear-resistance. Tribol Int 118: 373-380 (2018)

[82] Wu L P, Xie Z J, Gu L, Song B Y, Wang L Q. Investigation of the tribological behavior of graphene oxide nanoplates as lubricant additives for ceramic/steel contact. Tribol Int 128: 113-120 (2018)

[83] Zhao F Y, Zhang L G, Li G T, Guo Y X, Qi H M, Zhang G. Significantly enhancing tribological performance of epoxy by filling with ionic liquid functionalized graphene oxide. Carbon 136: 309-319 (2018)

[84] Jaiswal V, Kalyani, Umrao S, Rastogi R B, Kumar R, Srivastava A. Synthesis, characterization, and tribological evaluation of $\mathrm{TiO}_{2}$-reinforced boron and nitrogen codoped reduced graphene oxide based hybrid nanomaterials as efficient antiwear lubricant additives. ACS Appl Mater Interfaces 8(18): 11698-11710 (2016)

[85] Dedryvère R, Laruelle S, Grugeon S, Gireaud L, Tarascon J M, Gonbeau D. XPS identification of the organic and inorganic components of the electrode/ electrolyte interface formed on a metallic cathode. $J$ Electrochem Soc 152(4): A689 (2005)

[86] Leroy S, Martinez H, Dedryvère R, Lemordant D, Gonbeau D. Influence of the lithium salt nature over the surface film formation on a graphite electrode in Li-ion batteries: An XPS study. Appl Surf Sci 253(11): 4895-4905 (2007)

[87] Verma Y L, Singh R K. Conformational states of ionic liquid 1-ethyl-3-methylimidazolium Bis (Trifluoromethylsulfonyl) imide in bulk and confined silica nanopores probed by crystallization kinetics study. J Phys Chem C 119(43): 24381-24392 (2015)

[88] Nasybulin E, Xu W, Engelhard M H, Nie Z M, Burton S D, Cosimbescu L, Gross M E, Zhang J G. Effects of 
electrolyte salts on the performance of $\mathrm{Li}-\mathrm{O}_{2}$ batteries. The J Phys Chem C 117(6): 2635-2645 (2013)

[89] Khan T, Koide S, Tamura Y, Yamamoto H, Morina A, Neville A. Effects of using alternative Extreme Pressure (EP) and Anti-wear (AW) additives with oxy-nitrided samples. Tribol Lett 66: 43 (2018)

[90] Raviv U, Klein J. Fluidity of bound hydration layers. Science 297(5586): 1540-1543 (2002)

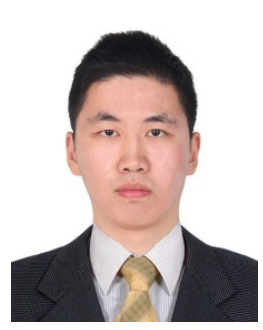

Hongdong WANG. He got his Ph.D. degree from State Key Laboratory of Tribology at Tsinghua University in 2018 and now is a

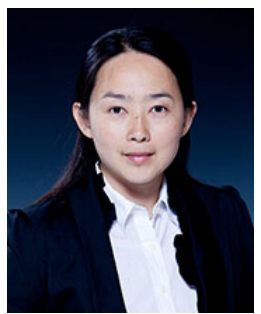

Yuhong LIU. She received her Ph.D. degree in Chinese Academy of Sciences Key Laboratory of Molecular Nanostructure \& Nanotechnology Institute of Chemistry, Chinese Academy of Sciences, Beijing, China, in 2005. She is an
[91] Han T Y, Zhang C H, Chen X C, Li J J, Wang W Q, Luo $\mathrm{J}$ B. Contribution of a tribo-induced silica layer to macroscale superlubricity of hydrated ions. J Phys Chem C 123(33): 20270-20277 (2019)

[92] Liu Y F, Li J J, Ge X Y, Yi S, Wang H D, Liu Y H, Luo J B. Macroscale superlubricity achieved on the hydrophobic graphene coating with glycerol. ACS Appl Mater Interfaces, 12(16): 18859-18869 (2020)

postdoctor at Tsinghua University. His research topics focus on the water-based superlubricity and the application of 2D nanomaterials in tribology.

associate professor at the State Key Laboratory of Tribology of Tsinghua University, China, from 2005. Her research areas cover nanotribology, nanostructure, nanotechnology of surface and interface, chemicalmechanical planarization, and water-based lubrication. 